\title{
Use of inhaled devices during a hospital exacerbation of COPD: a summary of an interdisciplinary audit held at ICS Maugeri Pavia, Italy (March-June 2019)
}

\author{
Michele Vitacca ${ }^{1}$, Cinzia Lastoria ${ }^{2}$, Monica Delmastro ${ }^{2}$, Domenico Fiorenza ${ }^{1}$, Pasquale De Cata ${ }^{2}$, \\ Barbara Fusar Poli ${ }^{2}$, Sonia Gilè ${ }^{3}$, Paola Prometti ${ }^{1}$, Mara Paneroni ${ }^{1}$, Cristina Bianchi ${ }^{2}$, Elena Mandora ${ }^{1}$, \\ Roberta Porri 2 , Claudio Fracchia ${ }^{1}$ \\ Department of Respiratory Rehabilitation, ICS Maugeri IRCCS ${ }^{1}$ Institute of Lumezzane (BS); ${ }^{2}$ Institute of Pavia; \\ ${ }^{3}$ Institute of Montescano (PV), Italy
}

\begin{abstract}
To date treatment protocols in Respiratory and or Internal departments across Italy for treatment of chronic obstructive
\end{abstract}

\begin{abstract}
Correspondence: Michele Vitacca, Istituti Clinici Scientifici Maugeri IRCCS, Department of Respiratory Rehabilitation, Via Salvatore Maugeri 4, 27100 Pavia, Italy.

E-mail: michele.vitacca@icsmaugeri.it
\end{abstract}

Key words: Relapse; inhaled therapy; devices; COPD.

Contributions: MV has full access to all the data in the study and takes responsibility for the integrity of the data and the accuracy of the data analysis. All the Authors contributed substantially to data analysis and interpretation, and to the writing of the manuscript. All the Authors approved the final version of the manuscript and declare that questions related to the accuracy or integrity of any part of it have been appropriately investigated and resolved. MV, as corresponding author, has been identified as guarantor of the paper, taking responsibility for the integrity of the work as a whole, from inception to published article.

Conflict of interest: MV has perceived grants for intellectual consultations from Chiesi, Boehringer Ingelheim, Glaxo, Menarini, Vivisol, Sapio Life, Phylips, Fischer and Packel.

$\mathrm{CL}$ and $\mathrm{PP}$ have perceived grants for intellectual consultations from Boehringer Ingelheim.

MD, PDC, CF, DF, MP, CB, EM, RP, SG and BFP have no perceived financial or have personal conflict of interest that might bias the content of this manuscript.

Funding: This workshop was partly funded by: 1) an unrestricted sponsorship from Boehringer Ingelheim and Vivisol; 2) the "Ricerca Corrente" Funding scheme of the Ministry of Health, Italy.

Acknowledgements: We acknowledge Laura Comini and Adriana Olivares for their editorial help.

Received for publication: 30 September 2019

Accepted for publication: 8 January 2020.

${ }^{\circ}$ Copyright: the Author(s), 2020

Licensee PAGEPress, Italy

Monaldi Archives for Chest Disease 2020; 90:1176

doi: 10.4081/monaldi.2020.1176

This article is distributed under the terms of the Creative Commons Attribution Noncommercial License (by-nc 4.0) which permits any noncommercial use, distribution, and reproduction in any medium, provided the original author(s) and source are credited. pulmonary disease (COPD) patients at hospital admission with relapse due to exacerbation do not find adequate support in current guidelines. Here we describe the results of a recent clinical audit, including a systematic review of practices reported in literature and an open discussion comparing these to current real-life procedures. The process was dived into two 8-hour-audits 3 months apart in order to allow work on the field in between meeting and involved 13 participants ( 3 nurses, 1 physiotherapist, 2 internists and 7 pulmonologists). This document reports the opinions of the experts and their consensus, leading to a bundle of multidisciplinary statements on the use of inhaled drugs for hospitalized COPD patients. Recommendations and topics addressed include: i) monitoring and diagnosis during the first $24 \mathrm{~h}$ after admission; ii) treatment algorithm and options (i.e., short and long acting bronchodilators); iii) bronchodilator dosages when switching device or using spacer; iv) flow measurement systems for shifting to LABA+LAMA within $48 \mathrm{~h}$; v) when nebulizers are recommended; vi) use of SMI to deliver LABA+LAMA when patient needs SABA $<3$ times/day independently from flow limitation; vii) use of DPI and pre-dosed MDI to deliver LABA+LAMA or TRIPLE when patient needs SABA $<3$ times/day, with inspiratory flow $>30$ litres/min; viii) contraindication to use DPI; ix) continuation of LABA-LAMA when patient is already on therapy; $x$ ) possible LABA-LAMA dosage increase; $x i$ ) use of SABA and/or SAMA in addition to $\mathrm{LABA}+\mathrm{LABA}$; $\mathrm{xii}$ ) use of SABA+SAMA restricted to real need; xiii) reconciliation of drugs in presence of comorbidities; xiv) check of knowledge and skills on inhalation therapy; $\mathrm{xv}$ ) discharge bundle; xvi) use of MDI and SMI in tracheostomized patients in spontaneous and ventilated breathing.

\section{Introduction}

By current definition, exacerbation of COPD refers to the acute worsening of respiratory symptoms, requiring additional therapy [1] and is generally classified based on severity and health care resources utilization into three groups: can be treated at home, need for in-hospital treatment, or need for intensive care units (ICU) [1-12].

Most often exacerbations are triggered by non-adherence to therapy, anxiety, depression, smoking, environmental irritants, pollution [9], and infections ( $30 \%$ bacteria, viruses in $24 \%$ and both in $25 \%$ of cases) [10]. Over time the recurrence of exacerbation events leads to a greater loss of function over time (decline of $\mathrm{FEV}_{1}$ ) and a lower quality of life (2-8), worsening health and 
increasing the risk of hospital admissions (approximately 14\% at 1 month, $21-34 \%$ at 3 months, $25 \%$ at 1 year) and death (13.4\% at 6 months, $22 \%$ at 1 year and $35.6 \%$ at 2 years) [11].

Often COPD remains undiagnosed for many years until the exacerbation event. Indeed, as evidenced by an Italian study on COPD patients presenting at the ED for exacerbation, one third of the patients had never received diagnosis and treatment (they had never performed spirometry!) despite $83 \%$ of patients presenting moderate-to-very-severe COPD and 30\% already presenting respiratory failure [13].

Differential diagnosis for COPD should consider: pneumonia, pneumothorax, rib fractures, pleurisy, pulmonary thromboembolism, heart failure, heart arrhythmias and lung cancer.

Although GOLD guidelines propose therapeutic approaches during the acute phase, mode of administration, maintenance therapy and reassessment of inhaler technique, no RCTs currently provide high-quality evidence on this topic [1].

The clinical approach in the hospital setting is often hindered by therapeutic inertia of years relying on aerosol therapy. Little is known about the possibility or potential of using different devices [metered-dose inhaler (MDI), dry-powder inhaler (DPI) and Soft Mist $^{\mathrm{TM}}$ Inhaler (SMI)] during the acute phase, or on the margins of overlapping between aerosol therapy and devices, on the timing and criteria for exclusion of devices use. Yet, it is known that the choice of one device over another may have a ripple effect on the time of medical and nursing staff, optimization of economic resources, therapeutic effectiveness, patient literacy, patient adherence and eventually performance indicators.

In this report we summarize results of an audit focusing on the use of inhaled drugs during an exacerbation of COPD, in the context of hospital admission. The document and contents herein reflect expert opinion and consensus reached after a literature review, a discussion in the courtroom, and review of a few retrospective clinical cases. In detail, the objectives pursued in the audit included: i) to explore the evolution of the current organizational and drugs management model for COPD patient with hospital need; ii) to focus on the diagnostic, therapeutic, educational approach both at the time of admission and before discharge; iii) to bring out good practices according to the participants' experience.

\section{Methods}

Thirteen invited participants from health staff (3 nurses, 1 physiotherapist, 2 internists and 7 pulmonologists) met for an audit of two meetings ( 8 hours each), which were held three months apart to allow a final statement processing. After presentation of modalities of the consensus process, the chairman (MV) asked the group the following questions: Should inhalation therapy be started already in the "prodromic" phase of exacerbation? Which drugs and which devices should be used? When should the dosage be increased? Should the dosage be the same even in the postexacerbation recovery phase? How do we define the severity of exacerbation? Particular focus and discussion were devoted to the issue of comorbidities that heavily impact the organizational and clinical management of the COPD patient: the group wondered if and how the therapeutic diagnostic bundle should be changed in these cases.

Prior to the meeting, we had performed a systematic review of the literature based on the search of the keywords: "inhaled therapy during relapse and COPD", "drug therapy and COPD hospitalization", "drugs devices during relapse", "bundle for COPD during hospitalization". The results were shared during the first meeting by MV who gave an introductory lecture on the background. In particular, he presented an example of an operational bundle proposed by Irish colleagues [14], i.e. a list of actions (operational instructions) that must be indefinitely implemented in case of relapse requiring hospital admission. The chairman invited the group to discuss their real-life behaviours.

During the three-month period, statements from the meeting were summarized and proposed as a new operational bundle hypothesis based on the literature and what was discussed in the classroom. The second meeting was dedicated to re-discussing the bundle, sharing, comparing, confirming or modifying the items.

The chairmen presented the final statements and the focus group was invited to vote using a Delphi-like procedure [15]. Each statement was deemed approved if at least $70 \%$ of the group rated the statement with a rating $>$ of $7(0$, totally disagreed; 10 , totally in agreement). A final list of the statement was provided.

\section{Results}

The Audit group commented on and integrated the proposed Irish bundle [14] with additions of actions deemed unquestionable in the case of COPD relapse. The group discussed the need for an instability triage at admission, proposing the use of the NEWS score [16] which considers respiratory rate, oxygen saturation, supplementary oxygen need, body temperature, systolic pressure, heart rate and state of consciousness. The Audit Group agreed that the first action to take was to administer oxygen to the patient to maintain the oxygen saturation within $88 \%$ and $92 \%$. Participants propose the need to measure saturation with a pulse oximetry device at the time of admission. The group agreed on the need to perform arterial blood gas analysis within 30 min from admission and, in case of hypoxemia, to increase the inhaled fraction of oxygen $\left(\mathrm{O}_{2}\right)$. If $\mathrm{pH}$ was $<7.35$, provide non-invasive ventilation or transfer to an appropriate unit should be considered. Everyone agreed that pulse oximetry device alone is not reliable and that arterial blood gases analysis remains the gold standard. As to the literature review, sixty papers were identified and 24 (Supplementary Table 1) were considered relevant and focused on the topic of our audit. For a summary of the literature [17-40] on pharmacological classes, dosages and devices used for the treatment of exacerbated COPD requiring hospitalization, see Supplementary Table 1.

The working group approved the bundle that foresees the use of a 32 -agonist and/or of an anticholinergic drug (aerosol with SABA or SAMA), within $30 \mathrm{~min}$ from the patient's presentation. In general, the use of inhaled steroid was not recommended, due to the high obstruction in the airways and the low level of deposition guaranteed in the low airways, making oral or intravenous steroid administration preferable. During the meeting, participants reached consensus concerning the proposal to integrate the bundle to include venous access for each patient with respiratory impairment regardless of the department where the patient is hospitalized. The Audit group approved that laboratory and chest X-rays should be carried out within $2 \mathrm{~h}$ of patient's entry and antibiotics should be administered within $4 \mathrm{~h}$ if indicated.

The group discussed the scenario in which the patient with the relapse is already using the inhaled devices at home. The group discussed three possible therapeutic approaches: 1) maintenance of 
background therapy and addition of aerosol therapy add-ons; 2) maintenance of the underlying therapy by adding steroid orally and/or intravenously, without concurrent use of aerosol therapy; 3 ) upon relapse, revaluation and replacement of the device with a more suitable drug class or type of device combined with one of the two previous approaches. The discussion focused on the real applicability in the hospitalized patient of the use of all the devices related to the three classes (DPI, MDI, SMI), and whether some further measures or filters need to be implemented in the selection of the device. Some supported the need for maintain background therapy with the device, raising when possible the dosages of longacting and implementing therapy in the vein with steroids or antibiotics; others did deem it inappropriate and proposed to switch to SAMA and or SABA.

All agreed that better night coverage would be provided by an aerosol add-on approach to a long-acting device, or the exclusive use of the long-acting device, with a once or twice daily administration compared to the six or four times per day administration and to the 15 to $30 \mathrm{~min}$ inhalation time required by each standard aerosol session. It is also unanimously agreed that the device is not indicated in the following patients: large elderly people, suffering from Parkinson's or diabetic neuropathy or rheumatologic diseases, with a cognitive or low consciousness level, who have paradoxical breath.

In order to decide the timing of switching to the use of a device, the group underlined the lack of scientific evidence and tools to monitor an individual's ability to perform inhalation therapy, as well as lung mechanics during and after an exacerbation. In this regard, the audit group agreed that the ability to generate inhalation flow is required in order to transition to long-acting device therapy, particularly for the use of DPI; whereas, SMI offers an aerosol generation independent of the air flow rate.

Finally, the group focused on the pre-discharge phase and in particular on the educational need for COPD patients. The group analysed the proposal to use: 1) a fast questionnaire assessing the patient's literacy on the disease/drugs and skills to use medication correctly (drug/drugs name, drug/drugs dosage prescribed, time of drug/drugs delivery during the day, drug/drugs recognition among others, drugs usefulness, how to prepare, use and replace the drugs) both at admission and at discharge; 2) a structured ad hoc educational pathway (explanatory videos on each of the devices, nurse-patient frontal lessons, detailed slide presentation); 3) educational material to reinforce the skills required by the patient (pamphlets providing extensive information on inhalation systems and their method of drug administration, illustrated cards for each device).

Tables 1 to 5 show a summary of the final statements submitted to voting, and its "approved" or "rejected" status.

\section{Discussion}

The present work aimed to provide a critical appraisal of current clinical practices in light of guidelines, and identify weaknesses and actions toward improvement. Our main results evidenced great focus addressed to the issues of a bundle with multidisciplinary statements on the management approach of the hospital exacerbated COPD, describing methods of using aerosol therapy, inhalation therapy, timing of intervention, quality of the interventions and patient verification of the knowledge and skills of the prescribed inhalation therapy before discharge.

\section{Bundle at admission}

The Audit Group shared that it is appropriate to evaluate patient's exacerbations on the basis of their severity, considering 3 different levels (to be treated at home, in hospital, in intermediateintensive care or ICU), assessing different parameters: comorbidity, respiratory rate, COPD severity, hemodynamic conditions, persistence of symptoms, state of mental confusion, oxygenation level, haematochemical examinations, sputum, heart rate and the presence of arrhythmias [1,12]. The group shared GOLD criteria for the request of specialist assessment or hospitalization [1]: marked increase in the intensity of symptoms (e.g., appearance of breathlessness at rest), exacerbation in the patient classified as serious COPD, appearance of new objective signs (cyanosis, peripheral oedema), failure to respond to treatment, presence of important concomitant diseases (severe organ failure, diabetes), arrhythmias of new-onset, diagnostic doubt, advanced age, appearance of sensor disorder, non-self-sufficiency and/or lack of family support.

\section{Inhaled drugs protocol}

Currently, the main drug delivery system is by inhalator pathway. Following is a brief description of the most common devices with advantages and drawbacks: 1 . Pre-dosed MDI sprays that are practical to use, but require good coordination skills on behalf of the patient, as the drug must be sucked up at the exact same moment the drug is released from the canister. Because the product is released at high speed puffs, there is a high risk that it can be mainly deposited inside the mouth and without reaching the lungs and bronchi in the dose it should, justifying the recommendation for use spacers. 2. Dry Powder Inhalers (DPI) that are easier to use than pre-dosed MDI, require more inhaling effort either in terms of generation of the peak inspiratory flow and its maintenance 3. SMI (Respimat $\left.{ }^{\circledR}\right)$, which is a next-generation inhaler, allows, the easier inhalation of small microscopic particles of drug, by dispensing a long-lasting slow-speed cloud which reaches the depth in the bronchial tree, independently from the air flow rate. 4. Traditional Aerosol therapy that involves a high organizational impact by the medical-nurse staff and a continuous focus to ensure sanitation in order to avoid intra-hospital or home over-infections. In particular, the advantages of air-solid therapy lie in the fact that they can be used at any age, they do not contain propellants that can damage the atmosphere, require very little teaching in the clinic and they promote confidence in the patient because they generate visible fog for several minutes, so as to reassure him about taking the drug. Disadvantages include that they require more time to take than an MDI, DPI or SMI. Jet nebulizers require an adequate compressed air source and maintenance of infection control equipment.

As suggested by one study [17] different therapeutic modalities need to be taken into consideration based on the severity of the exacerbation. In the first level: SABA and/or SAMA, delivered by MDI with a portable spacer or sprayer as needed and, if necessary, a LABA; in the second level: like the first without LABA; in the third level: SABA and SAMA by MDI with spacer (2 puffs every 2-4 hours) and, even if the patient is under ventilation, consider administering a LABA.

In general, the literature (Supplementary Table 1) indicates, as first choice, SABAs (e.g., salbutamol MDI 100 g, 2-4 puffs every 
Table 1. If patient is naive to inhaled therapy.

\begin{tabular}{|c|c|c|c|}
\hline Action & When & What & Approved \\
\hline Perform a clinical triage for patient instability & At presentation & Using the NEWS scale & Yes \\
\hline Measure the $\mathrm{SpO}_{2}$ value & At presentation & With pulsed oximeter & Yes \\
\hline Optimize oxygen & Within 5 min & If $\mathrm{SatO}_{2}<93 \%$ add $\mathrm{O}_{2}$ for $\mathrm{SatO}_{2}>93 \%$ & Yes \\
\hline Start bronchodilator therapy & Within 15 min & $\begin{array}{l}\text { SAMA: Ipratropium (nebulizer) } 0.5 \mathrm{mg} \times 4 \text { times/day } \\
\text { SABA: Nebulized salbutamol at a dose of } 2.5 \text { (5) mg every } 20 \mathrm{~min} \\
\text { or Albuterol (nebulizer) } 0.5-2 \mathrm{mg} \times 4 \text { day or } 2.5 \mathrm{mg} \times 3 \text { day or } \\
5 \mathrm{mg} \times 2 \text { times/day }\end{array}$ & $\begin{array}{l}\text { Yes } \\
\text { Yes } \\
\text { Yes }\end{array}$ \\
\hline Use of the nebulizer & $\begin{array}{l}\text { If patient is in severe } \\
\text { distress condition } \\
\text { (paradoxical breathing), } \\
\text { highly compromised, } \\
\text { over elderly (> } 85 \text { years), } \\
\text { with low level of } \\
\text { consciousness, symptoms } \\
\text { of Parkinsonism, presence } \\
\text { of diabetic neuropathies, } \\
\text { poor cognitive level } \\
\text { measured with Minicog } \\
\text { or MMSE), symptoms } \\
\text { of rheumatological disease }\end{array}$ & Use the nebulizer & Yes \\
\hline Drug use competence & Within 15 min & Go for educational test & Yes \\
\hline Perform arterial blood gases (ABG) & $\begin{array}{l}\text { Within } 20 \text { min if highly } \\
\text { compromised }\end{array}$ & & Yes \\
\hline Take venous access & $\begin{array}{l}\text { Within } 20 \text { min if highly } \\
\text { compromised }\end{array}$ & 8 & Yes \\
\hline Prepare NIV if $\mathrm{pH}<7.35$ & Within 20 min & & Yes \\
\hline Use NIV if $\mathrm{pH}<7.30$ & Within 30 min & s & Yes \\
\hline Add steroid per os/ev if necessary & Within $2 \mathrm{~h}$ & 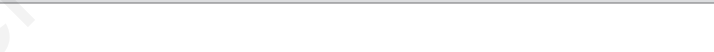 & Yes \\
\hline Add antibiotic if necessary & Within $2 \mathrm{~h}$ & & Yes \\
\hline Adjust the bronchodilator dosage & & $\begin{array}{l}\text { Salbutamol pressurized metered dose inhaler (MDI) } \\
100 \mu \mathrm{g} 2-4 \text { puffs every } 20 \mathrm{~min} \text { ) for } 1 \mathrm{~h} \\
\text { or } 200 \mu \mathrm{g} \text { x } 10 \text { times/day } \\
\text { Or } 400 \mu \mathrm{g} \times 7 \text { times/day } \\
\text { Or } 600 \mu \mathrm{g} \times 2 \text { times/day } \\
\text { Albuterol (MDI) 100-200 mg x } 4 \text { times/day } \\
\text { SAMA: Ipratropium (MDI) 18-36 mg x } 4 \text { times/day } \\
\text { Use the spacer when possible }\end{array}$ & $\begin{array}{l}\text { Yes } \\
\text { No } \\
\text { No } \\
\text { Yes } \\
\text { No } \\
\text { Yes } \\
\text { Yes }\end{array}$ \\
\hline New educational advice & Within $2 \mathrm{~h}$ & & Yes \\
\hline Require chest X-ray & Within $4 \mathrm{~h}$ & & Yes \\
\hline Require haematochemical tests & Within $4 \mathrm{~h}$ & & Yes \\
\hline Repeat ABG if in NIV & Within 1-2 h & & Yes \\
\hline Perform ABG & Within $4 \mathrm{~h}$ & & Yes \\
\hline $\begin{array}{l}\text { Add anticoagulant prophylaxis therapy } \\
\text { (if bedridden) }\end{array}$ & Within $4 \mathrm{~h}$ & Yes & \\
\hline Adjust bronchodilator prescription & Within 4, 12, $24 \mathrm{~h}$ & $\begin{array}{l}\text { Ipratropium MDI } 20 \mu \mathrm{g} 2-4 \text { puffs } \\
\text { Salbutamol MDI } 100 \mu \mathrm{g} 2-4 \text { puffs every } 4-6 \mathrm{~h}\end{array}$ & $\begin{array}{l}\text { Yes } \\
\text { Yes }\end{array}$ \\
\hline $\begin{array}{l}\text { Inspiratory flow meter (i.e., In-Check } \\
\text { DIAL G16), inhalation monitor } \\
\text { (i.e., Vitalograph } \text { AIM }^{\mathrm{TM}} \text { ) and MIP/MEP } \\
\text { manometer }\end{array}$ & & Useful for decision to long acting drugs/devices & Yes \\
\hline Adjust bronchodilator prescription & Within $48 \mathrm{~h}$ & If SABA <3 times/day;start LABA+LAMA delivered through a SMI & Yes \\
\hline Adjust bronchodilator prescription & Within $48 \mathrm{~h}$ & $\begin{array}{l}\text { If SABA }<3 \text { times/day and if inspiratory peak flow (PIF) } \\
>30 \mathrm{~L} / \text { min and/or MIP }>50 \% \text { consider a LABA+LAMA or } \\
\text { TRIPLE delivered through a DPI, pMDI and SMI }\end{array}$ & Yes \\
\hline Adjust bronchodilator prescription & Within $48 \mathrm{~h}$ & $\begin{array}{l}\text { If } \mathrm{PIF}<30 \mathrm{l} / \mathrm{min} \text { and } / \text { or MIP }<50 \% \text { do not use } \mathrm{DPI} \text {, prefer SMI } \\
\text { or pMDI }\end{array}$ & Yes \\
\hline
\end{tabular}


20') or SAMAs (e.g., Ipratropium MDI 18-36 mcg ,4 times a day) alone or the associations SABA-SAMA or SABA-LAMA. MDI and sprayers seem to be equivalent (it is recommended to use the spacer almost always). SAMAs appear to cause fewer adverse events than SABAs. The literature also recommends starting with nebulizers (in which oxygen should never be inserted) and then switching to the use of MDI. Nebulizers are recommended in patients with very high distress, with severe disease, very elderly ( $>85$ years), with a low level of consciousness. Furthermore, the literature suggests that the adjustment of the therapy involves the addition of SAMA (e.g.,
Ipratropium MDI $20 \mathrm{~g}, 2-4$ puffs) and SABA (e.g., salbutamol MDI $100 \mathrm{~g}, 2-4$ puffs) every 4-6 h. In order to treat the patient in an acute phase with the correct therapy, the literature proposes a check-list to reduce doses before discharge: once the patient's administrations of SABA or SAMA are reduced to less than 3 times a day, he/she may be converted to the inhalable therapy (LABA-LAMA or triple with steroid) with the trend being monitored over time.

In summary, despite the lack of strong evidence from RCTs, conclusions drawn from the audit process support the use of shortacting inhaled $\beta 2$-agonists -with or without short-acting

Table 2. If patient is yet under LABA+LAMA.

\begin{tabular}{|c|c|c|c|}
\hline Action & When & What & Approved \\
\hline Start bronchodilator therapy & Within 15 min & Do not suspend LABA+LAMA if in therapy & Yes \\
\hline Start bronchodilator therapy & Within 15 min & $\begin{array}{l}\text { Re-evaluate the LABA+LAMA device based on its inhalability } \\
\text { (e.g., inspiratory flow), preferring SMI over DPI in presence } \\
\text { of flow limitation }\end{array}$ & Yes \\
\hline Start bronchodilator therapy & Within 15 min & Increase LABA+LAMA dosage where applicable & Yes \\
\hline Start bronchodilator therapy on top & Within 15 min & $\begin{array}{l}\text { SAMA: Ipratropium (nebulizer) } 0.5 \mathrm{mg} \times 4 \text { times/day } \\
\text { SABA: Nebulized salbutamol at a dose of } 2.5 \text { every } 20 \mathrm{~min} \text { or } \\
\text { Albuterol (nebulizer) } 0.5 \mathrm{mg} \times 4 \text { times/day or } 2.5 \mathrm{mg} \times 3 \text { times/day } \\
\text { or } 5 \mathrm{mg} \times 2 \text { times/day }\end{array}$ & $\begin{array}{l}\text { Yes } \\
\text { Yes }\end{array}$ \\
\hline Adjust bronchodilator prescription & Within $2 \mathrm{~h}$ & $\begin{array}{l}\text { Continue with SABA + SAMA only if necessary } \\
\text { Salbutamol pressurized metered dose inhaler (MDI) } 100 \mu \mathrm{g} \\
2 \text { - } 4 \text { puffs every } 20 \text { min for } 1 \mathrm{~h} \\
\text { or } 200 \mu \mathrm{g} \text { x } 10 \text { day; or } 400 \mu \mathrm{g} \times 7 \text { day; or } 600 \mu \mathrm{g} \times 2 \text { times/day } \\
\text { Albuterol (MDI) } 100-200 \mathrm{mg} \times 4 \text { times/day } \\
\text { SAMA: Ipratropium (MDI) 18-36 mg x } 4 \text { times/day } \\
\text { Use spacer when possible }\end{array}$ & $\begin{array}{l}\text { Yes } \\
\text { Yes } \\
\text { Yes } \\
\text { Yes } \\
\text { Yes } \\
\text { Yes }\end{array}$ \\
\hline
\end{tabular}

Table 3. If patient presents comorbidities.

\begin{tabular}{llll}
\hline $\begin{array}{ll}\text { Action } \\
\text { Check for comorbidities }\end{array}$ & When & What & Approved \\
Add steroid per os/ev if necessary & Within $2 \mathrm{~h}$ & $\begin{array}{l}\text { Comprehensive assessment (assessing comorbidities and how to reconcile drugs } \\
\text { and dosages) }\end{array}$ & Beware of ICS dosage if the patient is diabetic \\
\hline Add antibiotic if necessary & Within $2 \mathrm{~h}$ & Beware of kidney and liver failures & Yes \\
\hline
\end{tabular}

Table 4. admission-discharge bundle treatment

\begin{tabular}{lll} 
Action & When & What \\
Check inhaled medications & $\begin{array}{l}\text { Both at presentation and at aved } \\
\text { hospital discharge }\end{array}$ & $\begin{array}{l}\text { Use a survey to check knowledge and skills for the use of inhalation } \\
\text { therapy }\end{array}$ \\
Pre-discharge bundle & $\begin{array}{l}\text { Within } 24 \text { h since hospital } \\
\text { discharge }\end{array}$ & $\begin{array}{l}\text { Advise about smoking stop, take appointment at no-smoking centre, } \\
\text { check if respiratory rehabilitation is necessary, check knowledge } \\
\text { and skills on devices, deliver educational material, give a control/ } \\
\text { surveillance appointment }\end{array}$ \\
\hline
\end{tabular}

Table 5. Particular settings where to use SMI and MDI.

\begin{tabular}{lll} 
Action & Who & Approved \\
It is possible to use SMI/MDI & In tracheostomized patient under spontaneous breathing & Yes \\
It is possible to use SMI/MDI & In tracheostomized patient under invasive mechanical ventilation & Yes \\
\hline It is possible to use SMI/MDI & In patient under NIV & No \\
It is possible to use SMI/MDI & In patient using the spacer & Yes \\
\hline
\end{tabular}


anticholinergics- as first-line bronchodilators for acute treatment of a COPD exacerbation, and advise against the use of MDI [1]. The strategy proposed is to increase frequency and dose of SABA, combining SABA and SAMA, considering LABA/LAMA once the patient becomes stable, and using the spacer or nebulizer when appropriate [1]. Maintenance therapy with long-acting bronchodilators should be initiated as soon as possible before hospital discharge. At the same time, in absence of a randomized, non-inferiority or superiority study, current evidence and GOLD lines suggest maintaining previous therapy with LABA or LAMA and switch to the aerosol pathway (via mask) in the first 24-48 h only in case of ineffectiveness or inability to use MDI [1]. GOLD guidelines stress that, during follow up, doctors must check maintenance therapy and reassess inhaler technique [1].

\section{Timing for devices}

Another concept to consider is lung function variability from patient to patient but also in the same patient and within a same day [41], which underscores the need for monitoring tools. In reference to this latter aspect, one interesting paper [42] describing a prodromic phase at the peak of breathlessness caused by the exacerbation, evidenced the need for tools that monitor day by day changes of breathing rate and other functional signals. The same paper demonstrated the need for a long period (about 30 days) for the patient to return to his previous phase of stability, with $20 \%$ of patients who had not returned to stability even after 35 days of exacerbation [42]. The patient with COPD may be characterized during exacerbations by a suboptimal peak inspiratory flow [43] that would affect a patient's ability to receive medication effectively and has been shown to be independently predictive of hospital COPD readmissions [44]. Therefore, in order to optimize two critical points of the COPD patient's hospitalization (i.e., the exacerbations phase and the educational phase before discharge), our ICS Maugeri team agreed to introduce a standardized step to re-evaluate -once within the first $48 \mathrm{~h}$ from admission, and then every two days - the inhaler used to deliver the bronchodilation. In pursuit of this aim, the group identified among the literature reviewed four different proposals: i) the Resmon Pro system that using the technique of forced oscillations (FOT) [45] measures the mechanical properties of the lungs and airways allowing monitoring of patient resistance by focusing in particular on the extent of expiratory flow limitation (EFL). The system seems to be an accurate, repeatable test, non-invasive, fast, simple but expensive. ii) An inspiratory flow meter (i.e., In-Check ${ }^{\mathrm{TM}}$ DIAL G16) as a valuable tool to be used in the assessment of treatment options. This could provide great benefit in the coaching phase to improve patients' peak inspiratory flow supporting the proper selection of the single inhaler based on patient's inhalability [46]. iii) An inhalation monitor (i.e., Vitalograph AIM $^{\mathrm{TM}}$ ) useful to identify the most suitable inhaler's class (i.e., MDI, DPI, SMI) providing real-time feedback during the inhalation phase [46]. iv) A portable maximal inspiratory and expiratory pressures (MIP/MEP) manometer to be used at patient' bed [47] to monitor inspiratory muscles strength ability.

\section{Pre-discharge bundle}

The group agreed on the need for a simple, clear and short predischarge bundle on smoking topic, need for pulmonary rehabilitation, monitoring patients' knowledge and skills to inhaled therapy, delivery of educational material, post-discharge check appointment as a fundamental pillar to avoid the risk of hospital readmissions. For medicines administered orally, user training is relatively simple, as it only requires the ability to swallow a tablet. Using inhalators is more complex and requires the understanding and proper execution of a complex chain of actions. Training patients in the use of the inhaler devices is a crucial aspect of treatment efficacy, and prescribers or health professionals should regularly verify the patients' proficiency in the use of treatment. Training must be emphasized as a crucial part of treatment and must be amenable to patients and involve all healthcare professionals who care patient. Beyond patient training, there is no perfect device and additional research is needed by device manufacturers to make these devices more error-safe and user-friendly. As a practical matter, it might be necessary to define which patients are most likely to benefit from inhaler technique training (for example aged, naive to education, patient with low cultural level).

\section{Limitations}

This paper reflects only expert opinion and audit consensus and it is not a document of structured recommendations or guidelines. Moreover, we are confident that due to a lack of specific details on this topic, further open questions remain unsolved; this real word report may help the discussion for future behaviours.

\section{Conclusions}

The ICS Maugeri audit has led to a bundle with multidisciplinary statements on the management approach of the hospital exacerbated COPD, describing methods of using aerosol therapy, inhalation therapy, timing of intervention, quality of the interventions and patient verification of the knowledge and skills of the prescribed inhalation therapy before discharge.

\section{References}

1. Global Initiative for Chronic Obstructive Lung Disease (GOLD). 2019 Global Strategy for Prevention, Diagnosis and Management of COPD. Evidence-based strategy document for COPD diagnosis, management, and prevention, with citations from the scientific literature. Accessed on: 27 September 2019. Available at: https://goldcopd.org/gold-reports/

2. Fletcher C, Peto R. The natural history of chronic airflow obstruction. Br Med J 1977;1:1645-8.

3. Wilkinson TM, Donaldson GC, Hurst JR, et al. Early therapy improves outcomes of exacerbations of chronic obstructive pulmonary disease. Am J Respir Crit Care Med 2004;169 :1298-303.

4. Donaldson GC, Seemungal TA, Bhowmik A, Wedzicha JA. Relationship between exacerbation frequency and lung function decline in chronic obstructive pulmonary disease. Thorax 2002;57:847-52.

5. Donaldson GC, Seemungal TA, Patel IS, et al. Longitudinal changes in the nature, severity and frequency of COPD exacerbations. Eur Respir J 2003;22:931-6.

6. Seemungal TA, Donaldson GC, Paul EA, et al. Effect of 
exacerbation on quality of life in patients with chronic obstructive pulmonary disease. Am J Respir Crit Care Med 1998; 157:1418-22.

7. Groenewegen KH, Schols AM, Wouters EF. Mortality and mortality-related factors after hospitalization for acute exacerbation of COPD. Chest 2003;124:459-67.

8. Soler-Cataluña JJ, Martínez-García MA, Román Sánchez P, et al. Severe acute exacerbations and mortality in patients with chronic obstructive pulmonary disease. Thorax 2005;60:925-31.

9. Hurst JR, Wedzicha JA. Chronic obstructive pulmonary disease: the clinical management of an acute exacerbation. Postgrad Med J 2004;80:497-505.

10. Papi A, Bellettato CM, Braccioni F, et al. Infections and airway inflammation in chronic obstructive pulmonary disease severe exacerbations. Am J Respir Crit Care Med 2006;173:1114-21.

11. Almagro P, Calbo E, Ochoa de Echagüen A, et al. Mortality after hospitalization for COPD. Chest 2002;121:1441-8.

12. Rabe KF, Hurd S, Anzueto A, et al. Global Initiative for Chronic Obstructive Lung Disease. Global strategy for the diagnosis, management, and prevention of chronic obstructive pulmonary disease: GOLD executive summary. Am J Respir Crit Care Med 2007; 176:532-55.

13. Zoia MC, Corsico AG, Beccaria M, et al. Exacerbations as a starting point of pro-active chronic obstructive pulmonary disease management. Respir Med 2005;99:1568-75.

14. McCarthy C, Brennan JR, Brown L, et al. Use of a care bundle in the emergency department for acute exacerbations of chronic obstructive pulmonary disease: a feasibility study. Int J Chron Obstruct Pulmon Dis 2013;8:605-11.

15. Hasson F, Keeney S, McKenna H. Research guidelines for the Delphi survey technique. J Adv Nurs 2000;32:1008-15.

16. Smith GB, Prytherch DR, Meredith P, et al. The ability of the National Early Warning Score (NEWS) to discriminate patients at risk of early cardiac arrest, unanticipated intensive care unit admission, and death. Resuscitation 2013;84:465-70.

17. Celli BR, MacNee W, ATS/ERS Task Force. Standards for the diagnosis and treatment of patients with COPD:a summary of the ATS/ERS position paper. Eur Respir J 2004;23:932-46.

18. Turner MO, Patel A, Ginsburg S, FitzGerald JM. Bronchodilator delivery in acute airflow obstruction. A meta-analysis. Arch Intern Med 1997;157:1736-44.

19. Jouneaua S, Dresc M, Guerderd A, et al. Management of acute exacerbations of chronic obstructive pulmonary disease (COPD). Guidelines from the Société de pneumologie de langue française (summary). Rev Mal Respir 2017;34:282-322.

20. Gupta D, Agarwal R, Aggarwal AN, et al. Guidelines for diagnosis and management of chronic obstructive pulmonary disease: Joint ICS/ NCCP (I) recommendations. Lung India 2013;30:228-67.

21. Leuppi JD, Schuetz P, Bingisser R, et al. Short-term vs conventional glucocorticoid therapy in acute exacerbations of chronic obstructive pulmonary disease: the REDUCE randomized clinical trial. JAMA.2013;309:2223-31

22. Garvey C, Ortiz G. Exacerbations of chronic obstructive pulmonary disease. Open Nurs J 2012;6:13-9.

23. Lodewijckx C, Sermeus W, Vanhaecht K, et al. Inhospital management of COPD exacerbations: a systematic review of the literature with regard to adherence to international guidelines J Eval Clin Prac. 2009;15:1101-10.

24. Kopsaftis ZA, Sulaiman NS, Mountain OD, et al. Short-acting bronchodilators for the management of acute exacerbations of chronic obstructive pulmonary disease in the hospital setting: systematic review. Syst Rev 2018;7:213.
25. Sandhu SK, Chu J, Yurkovich M, et al. Variations in the management of acute exacerbations of chronic obstructive pulmonary disease. Can Respir J 2013;20:175-9.

26. Woods JA, Usery JB, Self TH, Finch CK. An evaluation of inhaled bronchodilator therapy in patients hospitalized for nonlife-threatening COPD exacerbations. South Med J 2011;104:742-5.

27. Snow V, Lascher S, Mottur-Pilson C. Joint Expert Panel on COPD of the American College of Chest Physicians and the American College of Physicians-American Society of Internal Medicine. The evidence base for management of acute exacerbations of COPD: clinical practice guideline, part 1 . Chest 2001;119:1185-9.

28. Stolz D, Barandun J, Borer H, et al. Diagnosis, prevention and treatment of stable copd and acute exacerbations of COPD: The Swiss Recommendations 2018. Respiration 2018;96:382-98.

29. Stoller JK. Clinical practice. Acute exacerbations of chronic obstructive pulmonary disease. N Engl J Med 2002;346:988-94.

30. Vogelmeier CF, Criner GJ, Martinez FJ, et al. Global strategy for the diagnosis, management, and prevention of chronic obstructive lung disease 2017 report: GOLD Executive Summary. Eur Respir J 2017;49. pii: 1700214.

31. McCrory DC, Brown C, Gelfand SE, Bach PB. Management of acute exacerbations of COPD: a summary and appraisal of published evidence. Chest 2001;119:1190-209.

32. O'Donnell DE, Aaron S, Bourbeau J, et al. Canadian Thoracic Society. Canadian Thoracic Society recommendations for management of chronic obstructive pulmonary disease - 2003 . Can Respir J 2003;10:11A-65A.

33. Papaioannou AI, Herodotou Y, Tomos I, et al. Ability of using different dry powder inhalers during COPD exacerbations. Pulm Pharmacol Ther 2018;48:211-6.

34. Pleasants RA, Wang T, Xu X, et al. Nebulized corticosteroids in the treatment of COPD exacerbations: Systematic review, meta-analysis, and clinical perspective. Respir Care 2018;63:1302-10.

35. Pradan L, Ferreira I, Postolache P. The quality of medical care during an acute exacerbations of chronic obstructive pulmonary disease. Rev Med Chir Soc Med Nat Iasi 2013;117:870-4.

36. Pretto JJ, McDonald VM, Wark PAB, Hensley MJ. Multicentre audit of inpatient management of acute exacerbations of chronic obstructive pulmonary disease: comparison with clinical guidelines. Intern Med J 2012;42:380-7.

37. Al-Faqawi M, Abuowda Y, Elmassry AE, Böttcher B. Management of chronic obstructive pulmonary disease exacerbations at the Nasser Medical Complex: a clinical audit. Lancet 2018;391:S5.

38. Buess M, Schilter D, Schneider T, et al. Treatment of COPD exacerbation in Switzerland: Results and recommendations of the European COPD Audit. Respiration 2017;94:355-65.

39. Chang CL, Sullivan GD, Karalus NC, et al. Audit of acute admissions of chronic obstructive pulmonary disease: inpatient management and outcome. Intern Med J 2007;37:236-41.

40. Cydulka RK, Rowe BH, Clark S, et al. Emergency department management of acute exacerbations of chronic obstructive pulmonary disease in the elderly: The multicenter airway research collaboration. J Am Geriatr Soc 2003;51:908-16.

41. Rodriguez-Roisin R. Toward a consensus definition for COPD exacerbations. Chest 2000;117:398S-401S.

42. Seemungal TA, Donaldson GC, Bhowmik A, et al. Time course and recovery of exacerbations in patients with chronic obstructive pulmonary disease. Am J Respir Crit Care Med 2000;161:1608-13. 
43. Al-Showair RA, Tarsin WY, Assi KH, et al. Can all patients with COPD use the correct inhalation flow with all inhalers and does training help? Respir Med 2007;101:2395-401.

44. Loh C, Lovings TM, Ohar JA. Low inspiratory flow rates predict COPD and all cause readmissions. Am J Respir Crit Care Med 2016;193:A1125.

45. Dellacà RL, Gobbi $\mathrm{A}$, Pastena $\mathrm{M}$, et al. Home monitoring of within-breath respiratory by a simple and automatic forced oscillation technique device. Physiol Meas 2010;31: N11-24.

46. Mahler DA. Peak inspiratory flow rate as a criterion for dry powder inhaler use in chronic obstructive pulmonary disease. Ann Am Thorac Soc 2017; 14:1103-7.

47. American Thoracic Society/European Respiratory Society. ATS/ERS Statement on respiratory muscle testing. Am J Respir Crit Care Med 2002;166:518-624. 